\title{
Caracterização física e físico-química dos frutos da cajazeira (Spondias mombin L.) e de suas polpas obtidas por dois tipos de extrator
}

\author{
Physical and physicochemical characterization of caja fruit \\ (Spondias mombin L.) and its pulp, obtained using two types of extractor
}

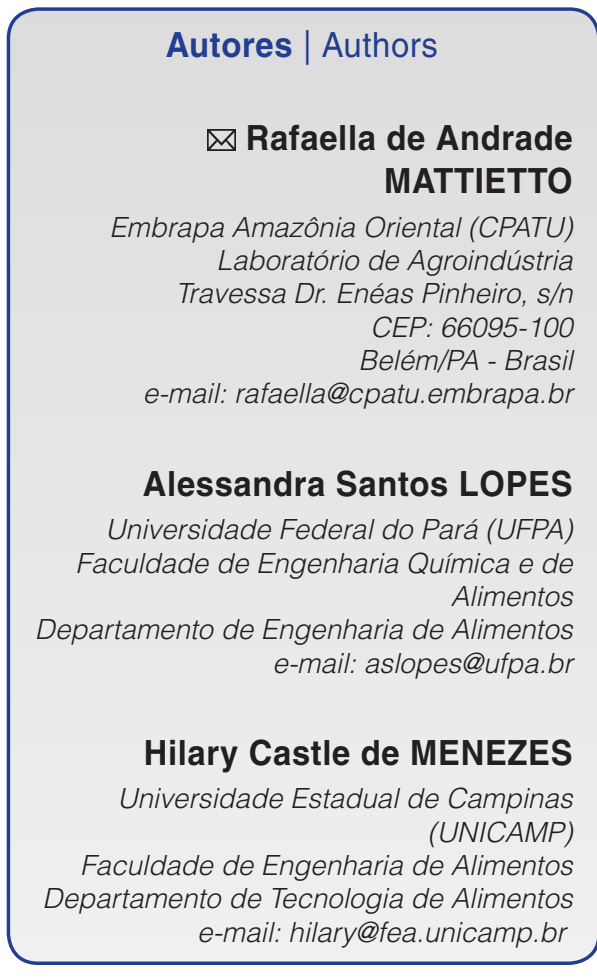

Autor Correspondente / Corresponding Author

Recebido / Received: 02/02/2009 Aprovado / Approved: 08/09/2010

\section{Resumo}

O cajá é um fruto amplamente consumido in natura ou na forma de produtos processados nas regiões Norte e Nordeste do Brasil. Devido à crescente aceitação de seus produtos e à busca por novos sabores, a agroindústria de sua polpa vem despertando interesse no mercado interno brasileiro e nas exportações. Entretanto, apesar do forte interesse comercial, poucos dados científicos sobre o fruto são encontrados. Assim, o objetivo desse trabalho foi caracterizar física e físico-quimicamente a polpa dos frutos provenientes de Belém-Pará, além de avaliar compostos relacionados à funcionalidade. Dessa forma, realizaram-se análises de composição centesimal, assim como determinação de pH, acidez titulável total, sólidos solúveis, açúcares totais e redutores, vitamina $\mathrm{C}$, taninos e carotenoides totais, além da avaliação instrumental de cor. A pesquisa também se propôs a avaliar dois tipos de equipamentos (pás e escovas) para um estudo comparativo da extração mecânica da polpa. Análises microbiológicas foram realizadas, características físico-químicas novamente estudadas, assim como o rendimento e a quebra de sementes durante as extrações foram avaliados. Os resultados revelaram que o fruto em estudo apresentou dimensões variáveis, com peso entre 1,35 e 16,47 g, com valor médio de 7,19 g. Em relação às características físico-químicas, a polpa foi considerada ácida ( $\mathrm{pH}$ de 2,53, acidez titulável de 1,86\% e baixo teor de açúcares totais de 4,54 g.100 $\left.\mathrm{g}^{-1}\right)$ e se destacou quanto aos teores de taninos (299,81 mg. $\left.100 \mathrm{~g}^{-1}\right)$ e carotenoides $\left(28,30 \mu \mathrm{g} .100 \mathrm{~g} \mathrm{~g}^{-1}\right)$. O tipo de extrator utilizado interferiu nestas características, sendo significativamente diferentes (Tukey a $p \leq 0,05$ ). O extrator do tipo escovas apresentou maior rendimento em polpa $(33,25 \%)$, maior teor de carotenoides totais $\left(38,56 \mu \mathrm{g} \cdot \mathrm{g}^{-1}\right)$, menor quebra de sementes e, consequentemente, um menor teor em taninos $\left(314,78 \mathrm{mg} .100 \mathrm{~g}^{-1}\right)$. Este mesmo extrator, quando comparado ao extrator de pás, também apresentou as melhores condições de processo para o fruto e melhor qualidade microbiológica do produto final.

Palavras-chave: Cajá; Caracterização; Extração da polpa; Taninos; Carotenoides. 


\section{Summary}

Caja is a fruit widely consumed fresh or in the form of processed products in the North and Northeast of Brazil. Due to the increasing acceptance of its products and the search for new flavours, the agroindustry processing these pulps is stimulating interest on both the internal Brazilian and exportation markets. However, despite the strong commercial interest, little scientific data on this fruit is available. Thus the objective of this study was to carry out a physical and physicochemical characterization of the fruit pulp from Belém/Pará, and evaluate the bioactive compounds. Thus the proximate composition was determined and also the $\mathrm{pH}$, total titratable acidity, soluble solids, total and reducing sugars, vitamin $\mathrm{C}$, tannins and total carotenoids, as well as carrying out an instrumental evaluation of the colour. Two types of extractor (blade and brush) were also compared for the mechanical extraction of the pulp. Microbiological analyses were carried out, the physicochemical characteristics studied again, and the yield and seed breakage during each type of extraction evaluated. The results showed that the caja fruit had variable dimensions, weighing between 1.35 and $16.47 \mathrm{~g}$, with an average weight of $7.19 \mathrm{~g}$. The pulp was considered acid ( $\mathrm{pH}$ of 2.53 , total titratable acidity of $1.86 \%$, showing low total sugar contents of $4.54 .100 \mathrm{~g} \mathrm{~g}^{-1}$ ) and stood out with respect to its contents of tannins $\left(299.81 \mathrm{mg} .100 \mathrm{~g}^{-1}\right)$ and carotenoids $\left(28.30 \mu \mathrm{g} . \mathrm{g}^{-1}\right)$. The type of extractor used interfered with these characteristics, being significantly different (Tukey, $p \leq 0.05$ ). The brush type extractor presented a greater yield in pulp (33.25\%), greater total carotenoid contents $\left(38.56 \mu \mathrm{g} . \mathrm{g}^{-1}\right)$, less seed breakage

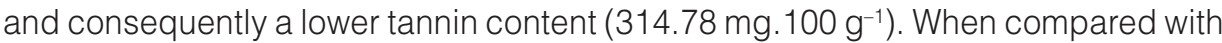
the blade extractor, the brush extractor also presented better process conditions for the fruit and for the microbiological quality of the final product.

Key words: Caja; Characterization; Pulp extraction; Tannins; Carotenoids. 


\section{Introdução}

Desde os tempos mais remotos, a caracterização de frutos in natura, sejam estes exóticos ou não, vem despertando o interesse da comunidade científica, pelo simples fato de se conhecer toda a potencialidade nutricional que os mesmos podem oferecer.

O Brasil é o país que apresenta a maior biodiversidade do mundo, o que permite acesso a inúmeras espécies frutíferas. Muitas delas são praticamente desconhecidas e, por tal motivo, são muito pouco exploradas comercialmente. As regiões Norte e Nordeste do país abrigam o berço maior dessa biodiversidade e, dentre uma infinidade de frutos tropicais lá encontrados, chama-se a atenção para o cajá.

O cajá é um fruto bem conhecido e cultivado em quase todo o Brasil, desde os tempos coloniais (BARBOSA et al., 1981; BOSCO et al., 2000). O fruto é extremamente aromático e rico em carotenoides, que dão à sua polpa, além de uma intensa coloração amarela, um apelo funcional bastante significativo. Junto aos carotenoides, o cajá possui um elevado teor de taninos, que faz com que a polpa do fruto ganhe destaque como provável antioxidante natural.

Rufino (2008), em recente pesquisa, avaliou frutos de cajá provenientes de Limoeiro do Norte-CE no aspecto funcional da polpa, obtendo bons resultados para atividade antioxidante pelos métodos de DPPH (9397,3 $\left.\mathrm{g} \cdot \mathrm{g}^{-1}\right)$, ABTS $\left(7,8 \mu \mathrm{mol}\right.$ Trolox. $\left.\mathrm{g}^{-1}\right)$, FRAP $\left(11,8 \mu \mathrm{mol} \mathrm{Fe}_{2} \mathrm{SO}_{4} \cdot \mathrm{g}^{-1}\right) \mathrm{e}$ sistema $\beta$-caroteno/ácido linoleico (inibição da oxidação em $92,7 \%$ ).

Alguns poucos trabalhos relacionados à biometria dos frutos de cajá, assim como a caracterização físicoquímica da polpa e/ou sua aplicação em produtos, vêm sendo estudados ao longo dos anos (BARBOSA et al., 1981; GOMES, 1985; BORA et al., 1991; FRANCO, 1992; DA SILVA et al., 1997, 1999; DIAS et al., 2003). Estudos físicos e químicos em genótipos também foram avaliados em frutos do Piauí e da Bahia (PINTO et al., 2003; SOARES et al., 2006), assim como o estudo pós-colheita e a modificação de constituintes químicos durante o amadurecimento foram avaliados em frutos procedentes de Pernambuco-PE (SAMPAIO et al., 2007).

Entre as operações mais comumente empregadas na indústria de alimentos para a preservação de frutas, está a extração de suas polpas, prática esta que visa facilitar a disponibilidade do produto para consumo ou insumo durante qualquer período do ano. Frutas muito perecíveis, como o cajá, têm nessa opção de conservação um menor desperdício de matéria-prima.

Os frutos da cajazeira apresentam boas características para a industrialização, em termos de rendimento e sabor. Segundo Barbosa et al. (1981), o percentual médio de rendimento em polpa é de $40 \%$ e pode ser compensado pelas características pronunciadas de aroma e sabor, apresentando amplas possibilidades industriais na fabricação de sucos, néctares, entre outros produtos. No Sul da Bahia, obtém-se um rendimento industrial entre 55 e $60 \%$ de polpa de cajá, dependendo da seleção efetuada antes do processamento (SACRAMENTO e SOUZA, 2000).

Por melhor que seja o método de extração aplicado, perdas em nutrientes vão ser observadas, especialmente vitaminas. Os carotenoides que se concentram nas camadas mais externas são perdidos, por exemplo, em processos que exigem a retirada da casca (SGARBIERI, 1987).

Segundo Rodriguez-Amaya (2002), a retirada da casca de frutas e a extração de seu suco resultam em perdas substanciais de carotenoides, podendo superar as de tratamentos térmicos. Sendo altamente insaturados, os carotenoides são susceptíveis a isomerização e oxidação. A liberação de ácidos orgânicos, quando as frutas são cortadas ou transformadas em sucos, é suficiente para provocar isomerização, causando ligeira perda de cor e alteração da atividade biológica. A desintegração também aumenta a exposição ao oxigênio e une os carotenoides e as enzimas que catalisam a oxidação. Por tais motivos, recomenda-se um processamento rápido e o uso de outra técnica de conservação logo após a extração.

Assim, o presente trabalho teve como objetivo caracterizar físico e físico-quimicamente o fruto em questão, além de testar como o tipo de extração pode influenciar nas características da polpa obtida, visando, dessa forma, um estudo comparativo que visualize um produto com maior rendimento e presença de compostos funcionais.

\section{Material e métodos}

\subsection{Material}

Os frutos da cajazeira foram adquiridos em feiras livres de Belém-PA, em estágio de maturação adequado para processamento. Acondicionados em sacos plásticos e lacrados, os frutos foram congelados e transportados em caixas de isopor, via aérea para Campinas-SP, sendo acondicionados a $-18{ }^{\circ} \mathrm{C}$ na câmara frigorífica da Faculdade de Engenharia de Alimentos - UNICAMP (DTA/FEA/UNICAMP). O lote armazenado continha aproximadamente $80 \mathrm{~kg}$ de frutos.

\subsection{Caracterização física}

Cerca de cem frutos foram escolhidos aleatoriamente no lote para a caracterização física. Com auxílio de um paquímetro, as medidas de comprimento e largura dos frutos foram determinadas. Manualmente, a separação da semente, polpa e casca foi realizada, e os rendimentos 
foram determinados através das respectivas massas, com auxílio de balança. O volume dos frutos foi determinado por imersão em água destilada à temperatura ambiente, contida em uma proveta graduada, através da medida da diferença de altura da coluna líquida após imersão. A densidade dos frutos foi calculada através da razão entre massa e volume.

\subsection{Caracterização físico-química}

As análises foram realizadas após o despolpamento dos cem frutos provenientes da caracterização física, da homogeneização da polpa e do acondicionamento em sacos plásticos apropriados. As amostras foram congeladas e as análises, a seguir relacionadas, realizadas em triplicatas.

- Umidade: método gravimétrico nº 920.151 da AOAC (CUNNIFF, 1997).

- Proteína: método de Kjeldahl, n 920.152 da AOAC (CUNNIFF, 1997).

- Lipídios totais: extração com mistura de solventes a frio, método de Bligh e Dyer (1959).

- Cinzas: método gravimétrico n 940.26 da AOAC (CUNNIFF, 1997).

- Fibra dietética: método enzimático-gravimétrico n 991.43 da AOAC (CUNNIFF, 1997).

- pH: com auxílio de um pHMETRO, segundo método n 981.12 da AOAC (CUNNIFF, 1997).

- Acidez titulável total: método n 942.15 da AOAC (CUNNIFF, 1997); acidez expressa em ácido cítrico.

- Açúcares totais e redutores: por titulação de oxirredução, método n 31.034-6 da AOAC (CUNNIFF, 1997).

- Sólidos solúveis: com auxílio de um refratômetro, segundo método n 932.12 da AOAC (CUNNIFF, 1997).

- Ratio: calculado através da relação entre sólidos solúveis totais e acidez total titulável, segundo Reed et al. (1986).

- Determinação de carotenoides totais: extração e quantificação segundo o método de RodriguezAmaya (1999)

- Vitamina C: o teor de ácido ascórbico foi determinado pelo método $n^{\circ} 43.065$ da AOAC (CUNNIFF, 1997) modificado por Benassi (1990), utilizando-se o solvente extrator ácido oxálico.

- Taninos: extração e quantificação pelo método colorimétrico de Folin-Denis n 952.03 da AOAC (CUNNIFF, 1997).

\subsection{Análise colorimétrica}

A determinação instrumental de cor foi realizada em quadruplicata através de um espectrofotômetro modelo Colorquest II marca Hunterlab, com reflectância especular incluída e iluminante $\mathrm{D} 65 / 10^{\circ}$. O sistema de leitura adotado foi o CIELab (HUNTER, 1975), representado pelos seguintes parâmetros: coordenada $L^{*}$ (luminosidade), coordenada de cromaticidade $a^{*}$ (-a verde, +a vermelho) e a coordenada de cromaticidade $b^{\star}$ (-b azul, +b amarelo). As amostras foram colocadas em uma cubeta de vidro de $1 \mathrm{~cm}$ com caminho opticamente limpo de $20 \mathrm{~mm}$ e a área de análise (campo de visão) de 1 polegada.

\subsection{Extração da polpa}

Os frutos, após o descongelamento, foram submetidos aos processos de lavagem (imersão e aspersão) e sanificação (imersão em solução aquosa de hipoclorito de sódio a 30 mg.L-1 , por 15 min).

As polpas foram extraídas em dois tipos de extratores disponíveis na planta piloto do DTA/FEA/ UNICAMP, conforme as especificações:

- Extrator de escovas, marca BERTUZZI, dotado de peneira com diâmetro equivalente a 0,8 mm de abertura de malha e capacidade de processo de $20 \mathrm{~kg}$ de fruto. $\mathrm{h}^{-1}$; e

- Extrator de pás, marca LANGSSENKAMI, dotado de peneira com diâmetro equivalente a 0,8 mm de abertura de malha e capacidade de processo de $10 \mathrm{~kg}$ de fruto. $\mathrm{h}^{-1}$.

\subsection{Avaliação das polpas extraídas}

As polpas foram acondicionadas em sacos de polietileno de baixa densidade $(24 \mathrm{~cm} \times 34 \mathrm{~cm} \times$ $0,15 \mathrm{~mm}$ ), em porções de $1 \mathrm{~kg}$, para facilitar o manuseio. Realizou-se um congelamento rápido, com auxílio de um congelador de placas (marca FRIGOSTRELLA DO BRASIL, modelo P.M-5). A câmara fria do DTA/FEA/ UNICAMP foi utilizada para manter as amostras estocadas a uma temperatura de $-18^{\circ} \mathrm{C}$.

Foram realizadas análises de $\mathrm{pH}$, acidez titulável total, teor de açúcares total e redutores, sólidos solúveis, taninos, carotenoides e cor, de acordo com os métodos anteriormente citados. As análises foram realizadas em triplicatas.

As análises microbiológicas de bolores e leveduras, contagem padrão, coliformes totais e fecais também foram efetuadas, de acordo com Vanderzant e Splittstoesser (1992), sendo utilizada uma amostra proveniente de cada extração. Realizou-se, porém, a incubação em quatro diferentes diluições $\left(10^{-1}, 10^{-2}, 10^{-3}, 10^{-4}\right)$, sendo as mesmas realizadas em duplicatas. 
Caracterização física e físico-química dos frutos da cajazeira (Spondias mombin L.) e de suas polpas obtidas por dois tipos de extrator

MATTIETTO, R. A. et al.

As extrações foram avaliadas quanto ao rendimento e à quebra de sementes (REED et al., 1986).

\subsection{Avaliação estatística dos resultados obtidos}

Visando a comparação entre as duas formas de extração, os resultados provenientes das análises físicoquímicas nos extratores foram submetidos ao teste de média Tukey, em um nível de significância de 95\%, com auxílio do software Statistica ${ }^{\circledR}$ versão 5.0 (STATSOFT, 1995).

\section{Resultados e discussão}

\subsection{Caracterização física}

Os resultados obtidos na caracterização física dos frutos da cajazeira e os rendimentos em polpa, casca e semente estão apresentados nas Tabelas 1 e 2 , respectivamente.

Existe uma grande escassez de dados quanto à caracterização física detalhada do cajá. A literatura encontrada mostra que o fruto apresenta comprimentos que vão de 3,50 até $6 \mathrm{~cm}$ (BARBOSA et al., 1981; GOMES, 1985; BORA et al., 1991).

Os frutos adquiridos no presente trabalho apresentaram-se bastante irregulares, característica que pode ser bem visualizada na Tabela 1, considerando-se os valores referentes ao comprimento e ao peso dos frutos. Porém, a irregularidade nas dimensões de frutos tropicais é bastante comum, tendo em vista a região produtora, a forma de cultivo, o clima da região, entre outros fatores que podem afetar as características de desenvolvimento dos frutos. Geralmente, frutos adquiridos em feiras livres apresentam características variáveis, justamente pelo fato de serem nativos de diferentes localidades.

A Tabela 2 mostra que o fruto possui sementes grandes, que corresponderam a $51,76 \%$ do peso total do fruto. O rendimento obtido em polpa foi baixo e as

Tabela 1. Resultados da caracterização física do cajá

\begin{tabular}{lrcc} 
& Máximo & Mínimo & Médio* $^{*}$ \\
Comprimento $(\mathrm{cm})$ & 4,85 & 1,50 & $2,93 \pm 0,60$ \\
Largura $(\mathrm{cm})$ & 2,73 & 1,33 & $2,18 \pm 0,27$ \\
Peso $(\mathrm{g})$ & 16,47 & 1,35 & $7,19 \pm 3,20$ \\
Densidade $\left(\mathrm{g} \cdot \mathrm{cm}^{-3}\right)$ & 1,40 & 0,63 & $0,94 \pm 0,38$ \\
\hline
\end{tabular}

* Média de cem determinações.

Tabela 2. Rendimentos calculados para o fruto cajá.

\begin{tabular}{cc} 
Fruto & Rendimento (\%) \\
Polpa & 24,2 \\
Casca & 13,8 \\
Semente & 51,8 \\
Perdas & 10,2 \\
\hline
\end{tabular}

perdas relativamente altas, devido à dificuldade no despolpamento manual do fruto. A casca fina, que reveste o fruto, é facilmente removida, porém a polpa é bastante aderida à semente. Por ser um fruto de alta umidade, as perdas em água foram inevitáveis, mesmo tomando-se o cuidado de usar anteparos durante os cortes e o despolpamento.

Bora et al. (1991) obtiveram a composição média de $32,81 \%$ sementes, $15,66 \%$ casca e $51,53 \%$ de polpa em trabalho com frutos de cajá provenientes de Itabaiana (PB).

\subsection{Caracterização físico-química}

A Tabela 3 apresenta os resultados da caracterização físico-química da polpa de cajá.

Nota-se que a polpa de cajá é ácida (pH de 2,53; acidez titulável de 1,86\%; baixo teor de açúcar 4,54 g.100 g-1), com alto teor de água em sua composição (89,42\% de umidade) e baixos valores de proteínas e lipídios, como a maioria das frutas. Em relação à fibra dietética, a fração solúvel correspondeu à maior parte $(0,75 \%)$. Os valores encontrados para as análises físicoquímicas e toda a composição centesimal do fruto estão de acordo com a literatura consultada (BARBOSA et al., 1981; BORA et al., 1991; FRANCO, 1992; DA SILVA et al., 1997, 1999; DIAS et al., 2003; PINTO et al., 2003). Da mesma forma, o valor de vitamina $\mathrm{C}$ encontrado, expresso em ácido ascórbico, está coerente com a literatura disponível (BORA et al., 1991; FRANCO, 1992; RUFINO, 2008).

Tabela 3. Caracterização físico-química da polpa de cajá.

\begin{tabular}{|c|c|}
\hline Análises & Resultados* \\
\hline $\mathrm{pH}$ & $2,53 \pm 0,01$ \\
\hline Acidez titulável total (\% ácido cítrico) & $1,86 \pm 0,01$ \\
\hline $\begin{array}{l}\text { Sólidos solúveis } \\
\text { (expressos em }{ }^{\circ} \text { Brix a } 28{ }^{\circ} \mathrm{C} \text { ) }\end{array}$ & $10,09 \pm 0,00$ \\
\hline Ratio & $5,42 \pm 0,01$ \\
\hline Umidade (\%) & $89,42 \pm 0,18$ \\
\hline Proteína (\%) & $0,82 \pm 0,01$ \\
\hline Lipídios totais (\%) & $0,26 \pm 0,09$ \\
\hline Cinzas (\%) & $0,58 \pm 0,02$ \\
\hline Fibra dietética (\%) & $1,18 \pm 0,10$ \\
\hline Fibra insolúvel (\%) & $0,43 \pm 0,12$ \\
\hline Fibra solúvel (\%) & $0,75 \pm 0,12$ \\
\hline Açúcares totais $\left(\mathrm{g} .100 \mathrm{~g}^{-1}\right)$ & $4,54 \pm 0,25$ \\
\hline Açúcares redutores $\left(\mathrm{g} .100 \mathrm{~g}^{-1}\right)$ & $4,25 \pm 0,34$ \\
\hline Açúcares não redutores $\left(\mathrm{g} .100 \mathrm{~g}^{-1}\right)$ & $0,29 \pm 0,27$ \\
\hline Carotenoides totais $\left(\mu \mathrm{g} \cdot \mathrm{g}^{-1}\right)$ & $28,30 \pm 0,18$ \\
\hline Taninos (mg.100 g ${ }^{-1}$ ) & $299,81 \pm 0,48$ \\
\hline Vitamina C (mg ácido ascórbico.100 g $\mathrm{g}^{-1}$ ) & $23,72 \pm 0,08$ \\
\hline
\end{tabular}

* Valores em base úmida, médias de três repetições. 
Quanto à análise de taninos, o valor encontrado no presente trabalho foi inferior àquele apresentado por Bora et al. (1991), sendo o valor médio obtido por estes autores de $420 \mathrm{mg} .100 \mathrm{~g}^{-1}$ de taninos. Da Silva et al. (1999), no estudo da polpa de cajá proveniente de Maranguape-CE, obtiveram valores bem inferiores aos

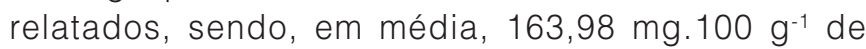
polpa.

O valor de carotenoides de $28,30 \mu \mathrm{g} \cdot \mathrm{g}^{-1}$ obtido é um pouco superior ao encontrado por RodriguezAmaya (1999), que observou o valor de 25,3 $\mu \mathrm{g} . \mathrm{g}^{-1}$. Em trabalho de pesquisa, Rodriguez-Amaya e Kimura (1989) analisaram a polpa de cajá por cromatografia em coluna aberta e determinaram a composição em carotenoides do fruto, indicando um valor total de 17,3 $\mu \mathrm{g} \cdot \mathrm{g}^{-1}$.

\subsection{Extração da polpa}

Os dados referentes ao rendimento dos dois extratores utilizados na obtenção da polpa de cajá são apresentados na Tabela 4.

Apesar de os valores apresentados sugerirem um rendimento baixo para o cajá, o mesmo pode ser considerado bom, pois o fruto apresenta sementes grandes, que são, em média, 51,76\% de sua composição.

Pode-se observar que o extrator de escovas apresentou um rendimento maior em relação ao de pás. Durante o processamento, observou-se a vantagem daquele extrator também em relação ao tempo de processo e à forma de alimentação dos frutos na máquina. No extrator de pás, as sementes dos frutos se prendiam entre elas e obstruíam assim a passagem de novos frutos para o despolpamento. O processo foi interrompido por diversas vezes para a retirada dessas sementes. Um aumento da velocidade de rotação causou um aquecimento da máquina, prejudicando assim a qualidade da polpa obtida. Em contrapartida, o extrator de escovas funcionou muito bem, com a polpa sendo extraída de forma fácil e sem manipulação.

Durante o despolpamento de frutos, é muito comum que os equipamentos, ao removerem a polpa, quebrem algumas sementes. Geralmente, os extratores que realizam o processo por uma tecnologia de abrasão (como escovas, por exemplo) quebram menos sementes

Tabela 4. Dados de rendimento em polpa dos extratores utilizados na obtenção da polpa de cajá.

\begin{tabular}{lcc} 
& \multicolumn{2}{c}{ Tipo de Extrator } \\
\cline { 2 - 3 } & Pás & Escovas \\
\hline Rendimento em polpa (\%) & 23,54 & 33,25 \\
Perdas* (\%) & 76,46 & 66,75 \\
Quebra & 28 pontos/5 g & 12 pontos $/ 5 \mathrm{~g}$ \\
\hline
\end{tabular}

* incluem-se sementes e cascas. do que aqueles que usam sistemas de corte, como pás ou facas. Conforme esperado, o extrator de pás apresentou um número maior de pontos escuros em cinco gramas de polpa. Sensorialmente, a quebra de sementes é um ponto importante na extração de uma polpa, pois compostos presentes no interior das sementes são liberados, principalmente aqueles que proporcionam amargor e/ou adstringência ao sabor.

A Tabela 5 mostra as análises físico-químicas nas polpas obtidas a fim de comparar os dois processos testados.

Observa-se que houve diferença significativa (Tukey a $p \leq 0,05)$ entre os extratores em todas as análises efetuadas, com exceção do teor de sólidos solúveis, que se manteve constante.

O resultado da análise de taninos confirma os resultados de quebra de sementes, pois o valor obtido para o extrator de pás indica uma maior liberação dos compostos para a polpa.

O valor de carotenoides obtido para o extrator de escovas foi superior, pelo fato de que, por trabalhar por atrito, o mesmo misturou grande quantidade de casca à polpa. A casca, conforme descrita anteriormente, é muito fina e de fácil remoção; assim, com o atrito das escovas entre o fruto e a peneira, a mesma acabou se desintegrando e misturando-se à polpa.

Pelas vantagens apresentadas, o extrator de escovas foi o escolhido como a melhor opção para o despolpamento de frutos como o cajá. Levando-se em consideração que a casca pode provocar modificações na composição, caracterizou-se novamente a polpa (Tabela 6).

Comparando-se os resultados obtidos com a Tabela 3 (polpa de cajá sem casca), nota-se um aumento significativo (Tukey a $p \leq 0,05$ ) nos teores de umidade, proteínas, lipídios, carotenoides e taninos na polpa com casca. O teor de sólidos solúveis sofreu uma redução, o que obviamente refletiu nos valores de açúcares totais e redutores.

Tabela 5. Análises físico-químicas da polpa de cajá extraída em equipamento de pás e escovas.

\begin{tabular}{lrr}
\multirow{2}{*}{\multicolumn{1}{c}{ Análises }} & \multicolumn{2}{c}{ Tipo de extrator } \\
\cline { 2 - 3 } & \multicolumn{1}{c}{ Pás } & \multicolumn{1}{c}{ Escovas } \\
$\mathrm{pH}$ & $2,9^{\mathrm{a}}$ & $2,77^{\mathrm{b}}$ \\
Acidez total titulável $(\%)$ & $1,09^{\mathrm{a}}$ & $1,28^{\mathrm{b}}$ \\
Sólidos solúveis $\left({ }^{\circ} \mathrm{Brix}\right.$ a $\left.20{ }^{\circ} \mathrm{C}\right)$ & $8,58^{\mathrm{a}}$ & $8,58^{\mathrm{a}}$ \\
Taninos $\left(\mathrm{mg} \cdot 100 \mathrm{~g}^{-1}\right)$ & $401,14^{\mathrm{a}}$ & $314,78^{\mathrm{b}}$ \\
Carotenoides totais $\left(\mu \mathrm{g} \cdot \mathrm{g}^{-1}\right)$ & $30,30^{\mathrm{a}}$ & $38,56^{\mathrm{b}}$ \\
\hline
\end{tabular}

Médias com letras iguais não apresentam diferença significativa (Tukey a $p \leq 0,05$ ). 


\subsection{Análise colorimétrica}

A Tabela 7 apresenta os resultados obtidos na análise de cor realizada na polpa de cajá in natura (extração manual) e após a extração mecânica.

Observa-se que a polpa in natura apresentou uma luminosidade maior, sendo que a extração mecânica dos frutos proporcionou uma queda significativa nesse valor, caracterizando assim certo escurecimento da polpa.

O cajá possui polpa de coloração amarela forte, tendendo, às vezes, ao alaranjado, resultado das cores vermelho $(+a)$ e amarelo (+b). Conforme esperado, os resultados de $b^{*}$ foram maiores, indicando a predominância da cor amarela no fruto. Em todos os parâmetros $\left(L^{*}, a^{*}\right.$ e $b^{*}$ ), a extração mecânica promoveu uma redução significativa dos valores (Tukey a $p \leq 0,05$ ).

\subsection{Análise microbiológica}

A Tabela 8 apresenta os resultados obtidos para a polpa de cajá nos respectivos extratores utilizados.

Tabela 6. Caracterização físico-química da polpa de cajá (polpa + casca) após despolpamento mecânico em extrator de escovas.

\begin{tabular}{lc}
\multicolumn{1}{c}{ Análises } & Resultados $^{*}$ \\
Umidade (\%) & $90,74 \pm 0,19$ \\
Proteína (\%) & $1,15 \pm 0,10$ \\
Lipídios totais (\%) & $0,45 \pm 0,05$ \\
Cinzas (\%) & $0,99 \pm 0,07$ \\
$\mathrm{pH}$ & $2,77 \pm 0,005$ \\
Acidez titulável total $(\%)$ & $1,28 \pm 0,005$ \\
Sólidos solúveis $\left({ }^{\circ} \mathrm{Brix} \mathrm{a} 20{ }^{\circ} \mathrm{C}\right)$ & $8,58 \pm 0,0005$ \\
Açúcares totais $\left(\mathrm{g} \cdot 100 \mathrm{~g}^{-1}\right)$ & $3,87 \pm 0,28$ \\
Açúcares redutores $\left(\mathrm{g} \cdot 100 \mathrm{~g}^{-1}\right)$ & $3,31 \pm 0,31$ \\
Açúcares não redutores $\left(\mathrm{g} \cdot 100 \mathrm{~g}^{-1}\right)$ & $0,56 \pm 0,29$ \\
Vitamina C (mg.100 $\left.\mathrm{g}^{-1}\right)$ & $27,65 \pm 0,06$ \\
Taninos (mg.100 $\left.\mathrm{g}^{-1}\right)$ & $314,78 \pm 0,37$ \\
Carotenoides totais $\left(\mu \mathrm{g} \cdot \mathrm{g}^{-1}\right)$ & $38,56 \pm 0,13$ \\
\hline
\end{tabular}

*Valores em base úmida, média de três repetições.

Tabela 7. Valores de luminosidade $\left(L^{*}\right)$ e coordenadas de cromaticidade $\left(a^{*}\right.$ e $\left.b^{*}\right)$ para polpa de cajá in natura e polpa extraída.

\begin{tabular}{ccc} 
& Polpa in natura & Extração escovas \\
$\mathrm{L}^{*}$ & $61,02^{\mathrm{a}}$ & $57,37^{\mathrm{b}}$ \\
$\mathrm{a}^{*}$ & $14,73^{\mathrm{a}}$ & $12,12^{\mathrm{b}}$ \\
$\mathrm{b}^{*}$ & $41,50^{\mathrm{a}}$ & $38,96^{\mathrm{b}}$ \\
\hline
\end{tabular}

Valores médios de três repetições e médias com letras iguais não apresentam diferença significativa (Tukey a $p \leq 0,05$ ).

Tabela 8. Análises microbiológicas da polpa extraída de cajá.

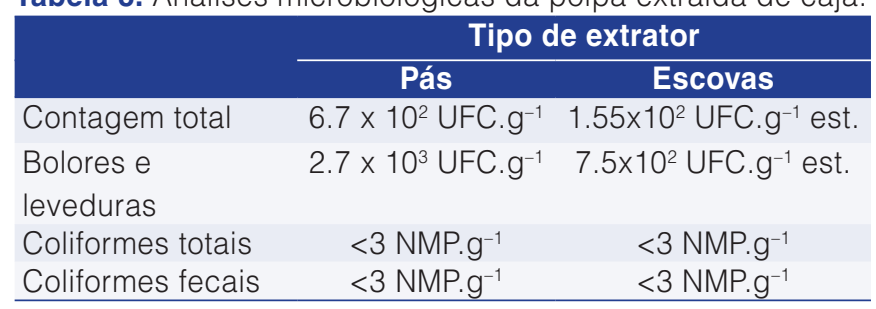

Os valores obtidos estão abaixo dos padrões máximos permitidos pela legislação em vigor e, portanto, essas polpas estão aptas para consumo ou armazenamento (BRASIL, 2000).

O Ministério de Estado da Agricultura e do Abastecimento em Instrução Normativa $n^{0} 01$, de 7 de janeiro de 2000, regulamenta padrões de identidade e qualidade para polpas de frutas e estabelece os valores máximos de $5 \times 10^{3}$ UFC.g-1 para bolores e leveduras (polpa in natura congelada ou não) e 10 NMP.g ${ }^{-1}$ para coliformes fecais.

O extrator de pás, embora apresente uma contaminação dentro dos padrões estabelecidos, mostra resultados bem superiores aos obtidos na extração com escovas. Acredita-se que essa contaminação seja resultado de uma maior manipulação durante o processo, uma vez que o mesmo foi interrompido por diversas vezes para retirada de sementes e cascas do fruto. Apesar de todos os cuidados de Boas Práticas de Fabricação realizados (uso de luvas descartáveis, aventais e toucas), a abertura do equipamento pode ter gerado um grau de contaminação maior.

\section{Conclusões}

A caracterização física dos frutos de cajá revelou um comprimento médio de $2,93 \mathrm{~cm}$ e peso médio de $7,19 \mathrm{~g}$. O fruto é constituído em maior parte por sementes, que correspondem a $51,76 \%$ do peso total.

A polpa de cajá pode ser considerada ácida (pH de 2,53 e acidez titulável de 1,86\%), com baixo teor de açúcar $\left(4,54\right.$ g.100 $\left.\mathrm{g}^{-1}\right)$ e alta umidade $(89,42 \%$ de umidade). Possui baixos teores de proteínas e lipídios, além de cinzas. Em relação à fibra dietética, a polpa apresentou 1,18\% em sua totalidade, sendo que a fração solúvel correspondeu à maior parte $(0,75 \%)$. A polpa também se destacou quanto aos teores de taninos

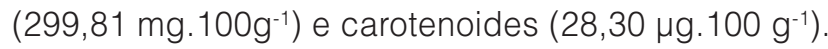

As polpas extraídas nos dois tipos de equipamentos diferiram entre si (Tukey a $p \leq 0,05$ ), sendo que o extrator do tipo escovas apresentou maior rendimento em polpa $(33,25 \%)$ e esta, maior teor de carotenoides totais $\left(38,56 \mu \mathrm{g} .100 \mathrm{~g}^{-1}\right)$; houve menor quebra de sementes (12 pontos/5 g) e, consequentemente, a polpa extraída com o equipamento do tipo escovas apresentou um menor teor em taninos $\left(314,78 \mathrm{mg} .100 \mathrm{~g}^{-1}\right)$, quando comparada à polpa extraída com o equipamento de pás.

A análise colorimétrica realizada na polpa in natura e após extração mecânica (tipo escovas) mostrou que o processo de extração afetou de maneira significativa (Tukey a $p \leq 0,05$ ) a cor da polpa obtida, com redução significativa da luminosidade $\left(L^{*}\right.$ de 61,02 a 57,37$)$ e das coordenadas ( $a^{*}$ de 14,73 a 12,12 e b* de 41,50 a $38,96)$. 
Caracterização física e físico-química dos frutos da cajazeira (Spondias mombin L.) e de suas polpas obtidas por dois tipos de extrator

MATTIETTO, R. A. et al.

A análise microbiológica realizada nas polpas extraídas mostrou uma maior contaminação naquela obtida pelo extrator de pás, devido ao maior manuseio e ao tempo de processo, indicando assim que o extrator do tipo escovas apresentou as melhores condições de processo para o fruto e para a qualidade microbiológica do produto final.

\section{Agradecimentos}

À Fundação de Amparo a Pesquisa do Estado de São Paulo (FAPESP), pelo apoio financeiro, e à UNICAMP, local onde efetivamente o trabalho foi desenvolvido.

\section{Referências}

BARBOSA, W. C.; NAZARÉ, R. F. R.; HASHIMOTO, K. Estudo bromatológico e tecnológico da graviola e do taperebá. Belém: Embrapa, 1981. 15 p. Boletim de pesquisa, n. 32.

BENASSI, M. T. Análise dos efeitos de diferentes parâmetros na estabilidade de vitamina $C$ em vegetais processados. 1990. 79 f. Dissertação (Mestrado em Tecnologia de Alimentos)Faculdade de Engenharia de Alimentos, Universidade Estadual de Campinas, Campinas, 1990

BISPO, E. S. Estudos de produtos industrializáveis de Umbu (Spondias tuberosa, Arr. Câmara). 1989. 60 f. Dissertação (Mestrado em Engenharia de Alimentos)-Faculdade de Engenharia de Alimentos, Universidade Federal do Ceará, Fortaleza, 1989

BLIGH, E. G.; DYER, W. J. A rapid method of total lipid extration and purification. Canadian Journal of Biochemistry and Physiology, Ottawa, v. 37, n. 8, p. 911-917, 1959.

BORA, P. S.; NARAIN, N.; HOLSCHUH, H. J.; VASCONCELOS, M. A. S. Changes in Physical and Chemical Composition during Maturation of Yellow Mombin (Spondias mombin) Fruits. Food Chemistry, Oxford, v. 41, n. 3, p. 341-348, 1991.

BOSCO, J.; SOARES, K. T.; AGUIAR FILHO, S. P.; BARROS, R. V. A cultura da cajazeira. João Pessoa: EMEPA-PB, 2000. 29 p.

BRASIL. Ministério de Estado da Agricultura e do Abastecimento. Instrução Normativa n 01 de 07 de janeiro de 2000. Diário Oficial da República Federativa do Brasil, Brasília, DF, 10 jan. 2000. seção I, p. 18166.

CUNNIFF P. A. (Ed.). Official methods of analysis of AOAC International. 16. ed. Gaithersburg: Patricia, 1997.

DA SILVA, A. P. V.; MAIA, G. A.; OLIVEIRA, G. S. F.; FIGUEIREDO, R. W.; BRASIL, I. M. Características da qualidade do suco polposo de cajá (Spondias lutea L.) obtido por extração mecânico-enzimática. Ciência e Tecnologia de Alimentos, Campinas, v. 17, n. 3 p. 233-724, 1997
DA SILVA, A. P. V.; MAIA, G. A.; OLIVEIRA, G. S. F.; FIGUEIREDO, R. W.; BRASIL, I. M. Estudo da produção do suco clarificado de cajá (Spondias lutea L.). Ciência e Tecnologia de Alimentos, Campinas, v. 19, n. 1, p. 33-36, 1999

DIAS, D. R.; SCHWAN, R. F.; LIMA, L. C. O. Metodologia para elaboração de fermentado de cajá (Spondias mombin L.). Ciência e Tecnologia de Alimentos, Campinas, v. 23, n. 3, p. 342-350, 2003.

FRANCO, G. Tabela de composição química dos alimentos 9. ed. Rio de Janeiro: Atheneu, 1992. 307 p.

GOMES, R. P. Fruticultura brasileira. 3. ed. São Paulo: Nobel, 1985. $58 \mathrm{p}$.

HUNTER, R. S. Scales for the measurement of colour difference. In: HUNTER, V. S. The measurements of appearance. New York: John Wiley, 1975. p.133-140.

PINTO, W. S.; DANTAS, A. C. V. L.; FONSECA, A. A. O.; LEDO, C. A. S.; JESUS, S. C.; CALAFANGE, P. L. P.; ANDRADE, E. M. Caracterização física, físico-química e química de frutos de genótipos de cajazeiras. Pesquisa Agropecuária Brasileira, Brasília, v. 38, n. 9, p. 1059-1066, 2003.

REED, J. B.; HENDRIX, D. L.; HENDRIX Jr., C. M. Quality control manual for citrus processing plants. Florida: Intercit, Safety Harbor, 1986. v. 1, 250 p.

RODRIGUEZ-AMAYA, D. B. Alterações de carotenóides durante processamento e estocagem de alimentos. In: BRAZILIAN MEETING ON CHEMISTRY OF FOOD AND BEVERAGES, 4., 2002, Campinas. Anais... Campinas: UNICAMP, 2002. 1 CD-ROM.

RODRIGUEZ-AMAYA, D. B. A guide to carotenoid analysis in foods. Washington: ILSI Press, 1999. 64 p.

RODRIGUEZ-AMAYA, D. B.; KIMURA, M. Carotenóides e valor de vitamina A em cajá (Spondias lutea). Ciência e Tecnologia de Alimentos, Campinas, v. 9, n. 2, p. 148-162, 1989.

RUFINO, M. S. M. Propriedades funcionais de frutas tropicais brasileiras não tradicionais. 2008. 237 f. Tese (Doutorado em Agronomia)-Universidade Federal Rural do Semi-Árido, Mossoró, 2008.

SACRAMENTO, C. K.; SOUZA, F. X. Cajá (Spondias mobin L.). Jaboticabal: FUNEP, 2000. 42 p. (Série Frutas Nativas).

SAMPAIO, S.A.; BORA, P.S.; HOLSCHUH, H.J.; SILVA, S.M. Postharvest respiratory activity and changes in some chemical constituents during maturation of yellow mombin (Spondias mombin) fruit. Ciência e Tecnologia dos Alimentos, Campinas, v. 27, n. 3, p. 511-515, 2007.

SGARBIERI, V. C. Efeitos dos vários processamentos sobre a qualidade dos alimentos. In: SGARBIERI, V. C. Alimentação 
Caracterização física e físico-química dos frutos da cajazeira (Spondias mombin L.) e de suas polpas obtidas por dois tipos de extrator

MATTIETTO, R. A. et al.

e nutrição: fator de saúde e desenvolvimento. São Paulo: Almed, 1987. cap. 14, p. 295-297.

SOARES, E. B.; GOMES, R. L. F.; CARNEIRO, J. G. M.; NASCIMENTO, F. N.; SILVA, I. C. V.; COSTA, J. C. L. Caracterização física e química de frutos de cajazeira. Revista Brasileira de Fruticultura, Jaboticabal, v. 28, n. 3, p. 518-519, 2006.
STATSOFT, INC. STATISTIC for Windows. Versão 5.0. Tulsa, USA, 1995

VANDERZANT, C.; SPLITTSTOESSER, D. F. Compendium of methods for the microbiological examination of food. 3. ed. Washington: American Public Health Association - APHA, 1992. 